\title{
A formação dos conceitos científicos na perspectiva da teoria- histórico-cultural: estudo teórico
}

\author{
Thiago Guimarães da Silva \\ Universidade de Uberaba - UNIUBE, Brasil \\ Ana Maria Esteves Bortolanza \\ Universidade de Uberaba - UNIUBE, Brasil \\ Apoio e financiamento: $\mathrm{CNPq}$
}

\section{RESUMO}

Este artigo tem como finalidade apresentar um estudo teórico sobre a formação dos conceitos científicos (2016) em Vigotski (2010 e Leontiev (2004). Trata-se de uma pesquisa teórica (DAVIDOV, 1988) realizada por meio de uma investigação conceitual para sistematizar o processo de formação dos conceitos científicos em relação aos conceitos espontâneos. São discutidos os fundamentos teóricos da formação humana na perspectiva histórico-cultural, o papel da linguagem na apropriação dos conceitos científicos e o processo de formação dos conceitos científicos em relação aos conceitos espontâneos. As considerações finais apontam a importância da organização do trabalho educativo do professor para a formação dos conceitos científicos dos alunos tendo em vista o desenvolvimento integral. Cabe a escola situar-se na esfera complexa da atividade humana fazendo a ponte com os conhecimentos da atividade empírica na vida cotidiana. Nesse contexto, o papel do professor como organizador do trabalho educativo é essencial para o desenvolvimento integral de seus alunos.

PALAVRAS-CHAVE: Teoria-Histórico-Cultural. Formação de Professores. Formação dos conceitos científicos. Atividade. Linguagem.

\section{THE FORMATION OF SCIENTIFIC CONCEPTS IN THE PERSPECTIVE OF THE HISTORICAL-CULTURAL THEORY: A THEORETICAL STUDY}

\begin{abstract}
This article aims to present a theoretical study on the formation of scientific concepts (2016) in Vigotski (2010 and Leontiev, 2004). This is a theoretical research (DAVIDOV, 1988) carried out through a conceptual research to systematize the theoretical foundations of human formation in the historical-cultural perspective, the role of language in the appropriation of scientific concepts and the process of formation of scientific concepts in relation to spontaneous concepts are discussed. The final considerations point out the importance of the organization of the educational work of the teacher for the formation of the scientific concepts of the students with a view to integral development. It is the school's place in the complex sphere of human activity that bridges the knowledge of empirical activity in everyday life. In this context, the role of teachers as organizers of educational work is essential for the integral development of their students.
\end{abstract}


KEYWORDS: Historical-Cultural Theory. Teacher training. Formation of scientific concepts. Activity. Language.

\section{LA FORMACIÓN DE LOS CONCEPTOS CIENTÍFICOS EN LA PERSPECTIVA DE LA TEORÍA-HISTÓRICO-CULTURAL: ESTUDIO TEÓRICO}

\section{RESUMEN}

Este artículo tiene como finalidad presentar un estudio teórico sobre la formación de los conceptos científicos (2016) en Vigotski (2010 y Leontiev (2004). Se trata de una investigación teórica (DAVIDOV, 1988) realizada por medio de una investigación conceptual para y en el sentido de que el proceso de formación de los conceptos científicos en relación a los conceptos espontáneos, se discuten los fundamentos teóricos de la formación humana en la perspectiva histórico-cultural, el papel del lenguaje en la apropiación de los conceptos científicos y el proceso de formación de los conceptos científicos en relación a los conceptos espontáneos Que se ha convertido en una de las más importantes de la historia de la ciencia y de la ciencia, en la vida cotidiana. En este contexto, el papel del profesor como organizador del trabajo educativo es esencial para el desarrollo integral de sus alumnos.

PALABRAS CLAVE: Teoría-Histórico-Cultural. Formación de profesores. Formación de los conceptos científicos. Actividad. Idioma.

\section{INTRODUÇÃO}

O aluno vivencia mudanças em suas relações ao entrar na escola. Ampliam-se suas vivências e as mudanças psicológicas são impulsionadas pela atividade de estudo, pois essa atividade nessa fase derivam lhe proporciona apropriar-se das máximas qualidades humanas historicamente produzidas pelo homem. A relação com as formas ideais da cultura humana possibilita ao aluno formar os conceitos científicos em diversas áreas do conhecimento como a linguagem, a literatura, a arte, a matemática, enfim os conhecimentos científicos.

Este estudo se propõe a apresentar o percurso da formação dos conceitos científicos em suas relações com a linguagem e outras funções psicológicas superiores. Para isso, foi realizada uma pesquisa teórica no sentido de se constituir uma investigação conceitual, sistemática baseada em dois autores Vigotski e Leontiev, na perspectiva histórico-cultural (DAVIDOV, 1988).

Nessa perspectiva, o aluno desenvolve o pensamento abstrato - inferir, deduzir, sistematizar, raciocinar, sintetizar, analisar - isto é, abstrair, própria da atividade guia nessa fase que é o estudo. Para formar as funções psicológicas, particularmente, o pensamento teórico, o aluno precisa formar os conceitos científicos incorporando nesse processo os conceitos espontâneos já formados na idade pré-escolar. 
Não se trata de desenvolver habilidades inatas de cada aluno, uma vez que, na perspectiva vigotskiana, estas são formadas nas relações sociais. Trata-se de educar pelo ensino dos conhecimentos científicos, e o papel do professor é organizar o trabalho educativo entre os conhecimentos científicos e os conhecimentos da vida cotidiana.

Para Marino Filho (2011, p. 29), é importante compreender que a "vida concreta, empírica, não ocupa, ela mesma, a centralidade da atividade de estudo, mas que é importante para a ligação de sentido entre estudo e vida real", ou seja, "que o estudante possa reconhecer o estudo como forma de atuação na sua integração social, de maneira que os conhecimentos adquiram para ele um sentido vital".

A vida empírica nos remete à questão dos conceitos espontâneos que se formam no cotidiano por meio das relações que os alunos experimentam com outras pessoas com as quais convivem. Para valorizar tais relações e os conceitos espontâneos, a atividade de estudo deve ser intencional a fim de que o aluno realize generalizações para construir os conceitos científicos atribuindo sentidos nesse processo.

É assim que, segundo Marino Filho (2011, p. 35), "a atividade de estudo, sendo escolarizada e constituída com conhecimentos da ciência, é, por sua vez, igualmente histórica e está diretamente correlacionada com os interesses sociais". Assim, "não se trata de uma atividade exclusivamente individual, produzida por atributos próprios de um sujeito abstrato. Cumpre conhecê-la no conjunto de sua estrutura, como atividade social” Marino Filho (2011, p. 35). Nesse sentido, a atividade de estudo torna-se instrumento de generalizações, aprendizagem e desenvolvimento.

Ressaltamos que a atividade de estudo em si, segundo a perspectiva vigotskiana, não é determinante para o fracasso ou o sucesso do processo de ensino dos conceitos. Ela possibilita a interação entre o professor mediador e o aluno e tem como objetivo promover e favorecer, primeiramente, a interação social, o que pode ser motivador e assim possibilitar uma educação desenvolvente que favorecendo a aprendizagem impulsione o desenvolvimento do indivíduo.

\section{FUNDAMENTOS TEÓRICOS DA FORMAÇÃO HUMANA NA PERSPECTIVA HISTÓRICO-CULTURAL}

Na perspectiva histórico-cultural, o homem não nasce humano, pois sua humanidade se encontra externa a ele. Assim, o processo de humanização se dá ao longo do processo de apropriação da cultura historicamente acumulada pelas gerações precedentes que as novas gerações encontram ao nascer, 
Leontiev (2004, p. 279) defende a "ideia de que o homem é um ser de natureza social, que tudo o que tem de humano nele provém da sua vida em sociedade, no seio da cultura criada pela humanidade”. Sua concepção de cultura baseia-se em Engels, que tendo conhecido a obra A origem das espécies de Charles Darwin mostra a origem animal do homem, destacando que este se diferencia de todas as espécies de animais. Estamos nos referindo a uma concepção de homem historicamente situado que se constrói a partir das relações sociais em determinada cultura.

A concepção de cultura nessa perspectiva tem como princípio que o homem se produz e se apropria da cultura na sociedade, sendo o trabalho a atividade humana principal na passagem do macaco para o homem. Dessa forma, "esta passagem modificou a sua natureza e marcou o início de um desenvolvimento que, diferentemente do desenvolvimento dos animais, estava e está submetido não às leis biológicas, mas às leis sócio-históricas” (LEONTIEV, 2004, p. 280).

À vista disso compreendemos que o homem se humaniza ao se inserir num mundo de fenômenos e objetos que trazem cristalizadas as marcas da cultura produzida historicamente. Para se apropriar da cultura o homem como ser social participa das diversas formas de atividade social, e, nesse processo, formam-se suas aptidões humanas. Podemos citar como exemplo a aptidão para empregar a linguagem articulada que se forma em cada indivíduo no processo de aprendizagem da língua. Assim também se desenvolvem o pensamento e outras funções psicológicas superiores.

A experiência sócio-histórica do homem acumula-se no mundo exterior, nos objetos materiais e imateriais -, de modo a produzir a história da natureza humana por meio da atividade prática que surge das necessidades criadas nesse processo. Nesse sentido, o homem transforma a cultura e é por ela transformado, ou seja, o homem se apropria da cultura e, simultaneamente, desenvolve suas faculdades interferindo nesse processo, constituindo-se humano e ao mesmo tempo transformando o mundo em que vive.

É por meio da atividade prática que o homem se desenvolve culturalmente. A linguagem tem um papel fundamental de mediar a apropriação e a objetivação dos conhecimentos construídos de geração em geração. Esse é um processo de educação, seja formal ou informal, e nele a atividade prática e a linguagem como um instrumento semiótico possibilitam significar o mundo da cultura e atribuir-lhe sentidos. É assim que se realiza o desenvolvimento humano. A atividade humana é, portanto, essencial para humanização do homem.

Leontiev (1983, p. 61) esclarece que a "a ideia da análise da atividade como método na psicologia científica do homem foi formulada nos primeiros escritos de L. S. Vigotsky". A 
atividade humana - o trabalho - é a unidade central da vida humana, trata-se de um "sopro vital do sujeito corpóreo" (LEONTIEV, 1983, p. 57, tradução nossa). Por meio da atividade, o homem se relaciona com o mundo. O processo de humanização, realiza-se pela atividade-guia do indivíduo - a brincadeira, o estudo, o trabalho - de acordo com a função dele no sistema das relações sociais. Por meio da atividade guia, o homem apropria-se das objetivações do gênero humano, de modo que as atividades são sempre conduzidas por motivos que coincidem com seus objetivos. Sem essa estrutura, não se trata de atividade, mas de ações.

Como se realiza o processo de apropriação da cultura e explicado por Vigotsky (2001, p. 40),

Desde os primeiros dias do desenvolvimento da criança, suas atividades adquirem um significado próprio num sistema de comportamento social e, sendo dirigidas a objetivos definidos, são refratadas através do prisma do ambiente da criança. $\mathrm{O}$ caminho do objeto até a criança e desta até o objeto passa através de outra pessoa. Essa estrutura humana complexa é o produto de um processo de desenvolvimento profundamente enraizado nas ligações entre história individual e história social.

A atividade prática externa do homem desenvolve também sua atividade interna, que tem a mesma estrutura, “origina-se a partir da atividade prática externa, não se separa dela, mas conserva com ela uma relação fundamental e bilateral" (LEONTIEV, 1983, p. 61, tradução nossa). Nessa perspectiva, a atividade é conceituada como "aqueles processos que, realizando as relações do homem com o mundo, satisfazem uma necessidade especial correspondente a ele”. (LEONTIEV, 1983, p. 52, tradução nossa).

De acordo com Leontiev (2004, p. 115):

A primeira condição de toda atividade é uma necessidade. Todavia, em si, a necessidade não pode determinar a orientação concreta de uma atividade, pois é apenas no objeto da atividade que ela encontra sua determinação: deve, por assim dizer, encontrar-se nele. Uma vez que a necessidade encontra sua determinação no objeto (se "objetiva" nele), o dito objeto torna-se motivo da atividade, aquilo que a estimula.

O reconhecimento dessas necessidades é descrito por Vigotsky (2001, p. 163) ao afirmar que "[...] toda aprendizagem só é possível na medida em que se baseia no próprio interesse da criança. Outra aprendizagem não existe".

Descrita por Leontiev (1983), a atividade é capaz de organizar internamente o próprio comportamento do homem, pois possibilita a articulação entre pensamento e a linguagem. Em resumo, a atividade se materializa por meio de ações e operações que são realizadas para atingir seu objetivo, num esquema que se estrutura em atividade-motivo-ação-objeto. 
São esses os fundamentos teóricos indispensáveis para a formação humana. Isto posto, destacamos que as atividades propostas em sala de aula devem provocar nos alunos necessidades em relação aos conhecimentos científicos que devem ser adquiridos nas interações sociais da sala de aula. Isso será possível somente se as atividades de estudo fizerem sentido para os alunos, isto é, se forem significativas. E, ainda, se a linguagem como instrumento mediador promover a apropriação dos conhecimentos científicos

\section{O PAPEL DA LINGUAGEM NA APROPRIAÇÃO DE CONCEITOS CIENTÍFICOS}

Para compreendermos melhor o papel da linguagem, se faz necessário delimitarmos que tipo de função é atribuído a ela, a linguagem. A linguagem tem duas funções básicas: de intercâmbio social e de pensamento generalizante. Tratando-se de intercâmbio social, Vigotsky (2010) mostra que a necessidade de nos comunicarmos leva ao desenvolvimento da linguagem e, que utiliza os signos linguísticos que expressam vontades, sentimentos, ideias, pensamentos, isto é, significados.

No pensamento generalizante, a linguagem é capaz de organizar o real, desenvolvendo todas as manifestações desse pensamento em categoria conceitual. O pensamento generalizante passa a ser um instrumento de pensamento, fornecendo os conceitos necessários para a compreensão dos objetos materiais e imateriais. Vigotsky (2010) esclarece que para compreender o funcionamento psicológico do ser humano é fundamental compreendermos as relações entre as duas funções psicológicas superiores: o pensamento e a linguagem.

O pensamento e a linguagem são geneticamente duas funções psicológicas com origens diferentes que se desenvolvem de forma diferente e independente, embora se relacionem no pensamento verbal. A história da humanidade, isto é, a filogênese e também a ontogênese, a história do desenvolvimento do indivíduo mostram como pensamento e linguagem foram formados historicamente e, nesse processo ontogenético e filogenético foram se formando os conceitos científicos nas diversas áreas de conhecimentos das ciências. O desenvolvimento do pensamento e da linguagem evidenciam a profunda e intrincada relação dessas duas funções que, embora tenham sua gênese separadamente, relacionam-se em sua formação (VIGOTSKI, 2000; 2001; 2006).

O processo histórico-cultural do pensamento e da linguagem no desenvolvimento filogenético e ontogenético remete às raízes que constituíram e constituem o próprio ser humano. O que podemos afirmar, na perspectiva histórico-cultural, é que tanto o pensamento quanto a linguagem têm raízes genéticas diferentes e que essas duas funções não estão ligadas 
entre si por um vínculo primário. Pelo contrário, elas aparecem, modificam-se e se ampliam num processo do próprio desenvolvimento do pensamento e da palavra, isto, é do pensamento verbal.

Para entendermos as propriedades do pensamento verbal ou discursivo como uma totalidade, uma unidade de análise do pensamento e da linguagem que contém as propriedades inerentes de ambas as funções psicológicas, não podemos fazer sua decomposição em elementos, mas em unidades de análise.

De acordo com as palavras de Vigotsky (2010, p. 397-398), é necessário:

[...] substituir a análise que aplica o método da decomposição em elementos pela análise que desmembra a unidade complexa do pensamento discursivo em unidades várias, entendidas estas como produtos da análise que, à diferença dos elementos, não são momentos primários constituintes em relação a todo fenômeno estudado mas apenas a alguns dos seus elementos e propriedades concretas, os quais, também diferentemente dos elementos, não perdem as propriedades inerentes à totalidade e são suscetíveis de explicação, mas contêm, em sua forma primária e simples, aquelas propriedades do todo em função das quais se empreende a análise.

Essa forma de análise revela o verdadeiro significado, fenômeno da palavra e do pensamento, nos remete ao todo, o que justifica pensarmos nela como unidade indecomponível de ambos os processos.

A partir dessas colocações, compreendemos que a palavra vista em seus aspectos sonoros, esvaziada de significado, é apenas um som vazio, assim como a palavra escrita sem significado é tão somente sinal gráfico. Nessa perspectiva, Vigotsky (2010) nos ensina a compreender melhor tal relação, ao tratar do significado como a unidade do pensamento verbal ou discursivo:

[...] o significado da palavra [...] é uma unidade do pensamento e da linguagem [...] é a própria palavra vista no seu interior [...] do ponto de vista psicológico o significado da palavra não é senão uma generalização ou conceito. Generalização e significado da palavra são sinônimos. Toda generalização, toda formação de conceitos é o ato mais específico, mais autêntico e mais indiscutível de pensamento. Consequentemente, estamos autorizados a considerar o significado da palavra como um fenômeno de pensamento. Assim, o significado da palavra é, ao mesmo tempo, um fenômeno de discurso e intelectual [...] é um fenômeno do pensamento discursivo ou da palavra consciente, é a unidade da palavra com o pensamento (VIGOTSKY, 2010, p. 398).

Se o conceito está na palavra e no pensamento, então isso é um ato de generalização. O desenvolvimento do conceito ou generalização mostra como se dá esse processo, tendo o 
significado como unidade de ambos. Assim, o significado é um fenômeno do pensamento e simultaneamente da linguagem constituindo a unidade da palavra no pensamento

Entendendo a relação entre pensamento e palavra, descobrimos que os significados se desenvolvem e, nessa perspectiva, ocorrem inúmeras possibilidades de organização do ensino a partir de conceitos espontâneos, que são apropriados pelos alunos no cotidiano, para a aprendizagem dos conceitos científicos que são sistematizados na escola.

\section{A FORMAÇÃO DOS CONCEITOS CIENTÍFICOS E SUA RELAÇÃO COM OS CONCEITOS ESPONTÂNEOS}

Iniciamos esta análise da concepção de conceitos utilizando uma citação dirigida ao professor: "O desenvolvimento dos conceitos científicos na idade escolar é, antes de tudo, uma questão prática de imensa importância - talvez até primordial - [...]”. A instituição escolar é responsável pela transmissão dos conhecimentos historicamente, "tem diante de si quando inicia a criança no sistema de conceitos científicos", a tarefa precípua de transmitir a herança cultural da humanidade (VIGOTSKY, 2010, p.241).

Esses pressupostos teóricos mostram que o conceito não é um conjunto de conexões associativas assimiladas com a ajuda da memória, muito menos um conjunto de hábitos mentais ativados automaticamente; pelo contrário, é um autêntico e complexo ato do pensamento humano.

Ao optar por uma teoria que explica a realidade para entender seu funcionamento, o professor tem diante de si as "ferramentas mentais" disponíveis. O processo de formação dos conceitos mostra que os primeiros conceitos vão ao encontro do cotidiano e são espontâneos ou pré-conceitos. Aos poucos dão lugar aos conceitos científicos que por sua própria natureza não são definitivos, desenvolvem-se e mudam no percurso escolar do aluno.

Os conceitos científicos se formam inicialmente pelas peculiaridades como a percepção das diferenças que ocorrem antes das percepções das semelhanças, devido ao nível de generalização necessária para esse fim. Sobretudo, o desenvolvimento dos pré-conceitos se dá na infância e vai sendo amadurecido ao longo da vida, a partir das relações do indivíduo com o meio e com o outro, nas interações sociais.

Para Vigotsky (2010, p.246), o conceito é, em termos psicológicos, “um ato de generalização e evoluem como os significados das palavras. "A essência do seu desenvolvimento é, em primeiro lugar, a transição de uma estrutura de generalização a outra", 
pois "em qualquer idade, um conceito expresso por uma palavra representa uma generalização". (VIGOTSKY, 2010, p. 246).

Ocorre uma evolução do significado das palavras. Para cada palavra nova, o processo se inicia e o desenvolvimento do aluno está apenas começando. O percurso de uma generalização elementar para um tipo de generalização mais elevada, que irá alavancar o conceito espontâneo ou pré-conceito ao patamar de conceito verdadeiro, ao ser incorporado pelo conceito científico em formação depende das condições de vida e de educação. Na escola, cabe ao professor organizar o trabalho educativo para que esse processo seja bem-sucedido.

Para que isso ocorra é necessário que o aluno desenvolva uma série de funções psicológicas superiores, principalmente o pensamento e a linguagem. Segundo Vigotsky (2010, p.246), "a atenção arbitrária, a memória lógica, a abstração, a comparação e a discriminação" são essenciais para tal desenvolvimento. Esses processos não devem ser "simplesmente memorizados, simplesmente assimilados", para que não ocorram erros recorrentes, em que o aluno não assimila o conceito, assimila a palavra, e em vez de desenvolver o pensamento, utiliza a memória para decorar as definições, sem compreender verdadeiramente os conceitos científicos para torná-los seus.

Vigotsky então concentra seus esforços em relação à construção da sua teoria sobre o desenvolvimento dos conceitos, esclarecendo que o caminho para a aquisição dos conceitos científicos percorre um caminho diferente da assimilação dos conceitos espontâneos.

[...] o caminho entre o primeiro momento em que a criança trava conhecimento com o novo conceito e o momento em que a palavra e o conceito se tornam propriedade da criança é um complexo processo psicológico interior, que envolve a compreensão da nova palavra que se desenvolve gradualmente a partir de uma noção vaga, a sua aplicação propriamente dita pela criança e sua efetiva assimilação apenas como elo conclusivo (VIGOTSKY, 2010, p.250).

O “o processo de desenvolvimento dos conceitos não termina, mas está apenas começando quando uma criança toma conhecimento pela primeira vez do significado de uma nova palavra", de acordo com Vigotski (2010, p. 250). Portanto, o trabalho educativo do está apenas começando quando o professor transmite para os alunos os conhecimentos científicos, utilizando para isso, principalmente, a linguagem verbal. Sem desconsiderar o percurso do aluno quando adquire os conceitos espontâneos, antes mesmo de adentrar a escola, o professor precisa identificar as generalizações dos alunos em sua disciplina para trabalhar os conceitos científicos.

Optar pelo ensino intencional e, portanto, consciente, requer do professor a compreensão do processo de formação dos conceitos. 
[...] o ensino consciente de novos conceitos e formas da palavra ao aluno não só é possível como pode ser fonte de um desenvolvimento superior dos conceitos propriamente ditos e já constituídos na criança, que é possível o trabalho direto com o conceito no processo de ensino escolar. [...] este trabalho não é o fim, mas o início do desenvolvimento do conceito científico, e não só não exclui os processos propriamente ditos de desenvolvimento como lhes dá uma nova orientação e coloca os processos da aprendizagem e desenvolvimento em novas relações maximamente favoráveis do ponto de vista dos objetivos finais da escola (VIGOTSKY, 2010, p.250).

Esse é o ponto fulcral dos fundamentos teóricos vigotskianos para o ensino dos conceitos científicos. Primeiramente identificar os conceitos já constituídos pelos alunos e a partir disso levá-los a um nível superior de conceituação, atuando na zona iminente de seu desenvolvimento, ou seja, para além daquilo que os alunos são capazes de realizar sozinhos.

Quando o aluno recebe ajuda de uma pessoa mais experiente que lhe fornece pistas, consegue solucionar um problema que não resolveria sozinho. Essa diferença entre a zona de desenvolvimento real e o nível de desenvolvimento que o aluno pode atingir ao resolver um problema é a zona de desenvolvimento iminente.

Essa discrepância entre a idade real ou nível de desenvolvimento atual, que é definida com o auxílio dos problemas resolvidos com autonomia, e o nível que ela atinge ao resolver problemas sem autonomia, em colaboração com outra pessoa, determina a zona de desenvolvimento imediato da criança (VIGOTSKY, 2010, p. 327).

$\mathrm{Na}$ medida entre a zona de desenvolvimento real e a zona de desenvolvimento iminente situa-se o processo dinâmico de desenvolvimento do aluno. Cabe esclarecer que, o aluno imita o que está na zona de desenvolvimento iminente, por isso a imitação deve ser vista no processo de ensino como um importante recurso para a aprendizagem. Porém não se trata de uma imitação mecânica: para imitar é preciso que o aluno possa passar daquilo que já sabe realizar para algo novo, desconhecido. De acordo com Vigotsky (2010, p. 329):

Em colaboração, a criança se revela mais forte e mais inteligente que trabalhando sozinha, projeta-se ao nível das dificuldades intelectuais que ela resolve, mas sempre existe uma distância rigorosamente determinada por lei, que condiciona a divergência entre a sua inteligência ocupada no trabalho que ela realiza sozinha e a sua inteligência no trabalho em colaboração (VIGOTSKY, 2010, p. 329).

Esse enfoque mostra que a imitação desempenha um papel tão relevante quanto a aprendizagem no processo de desenvolvimento de todas as funções psicológicas superiores, isto é, do desenvolvimento das qualidades humanas da consciência, das funções psicológicas superiores. A possibilidade de colaboração do professor na educação formal deve elevar a um 
plano superior o desenvolvimento do aluno. "Nisto se baseia toda a importância da aprendizagem para o desenvolvimento, e é isto o que constitui o conteúdo do conceito de zona de desenvolvimento imediato" (VIGOTSKY, 2010, p. 331).

Mediante essas considerações, a proposta para o ensino intencional tem como foco um tipo de aprendizagem que impulsiona o desenvolvimento infantil, portanto a aprendizagem age como motor desse desenvolvimento, ainda que nem todo aluno irá se desenvolver tendo uma boa aprendizagem. Ao optar por uma educação humanizadora, ou seja, uma educação para além do capital, privilegiamos as relações entre o ensino, a aprendizagem e o desenvolvimento humano.

A análise da relação entre os conceitos espontâneos e os conceitos científicos demostra que "conceitos científicos não se desenvolvem exatamente como os espontâneos, que o curso do seu desenvolvimento não repete as vias de desenvolvimento dos conceitos espontâneos" (VIGOTSKI, 2010, p. 252).

É indispensável ao professor compreender como ocorre o desenvolvimento dos conceitos espontâneos e os conceitos científicos e quais são as vias desse desenvolvimento seu desenvolvimento histórico, suas relações interfuncionais - em que ponto de sua história os conceitos espontâneos são incorporados pelos científicos.

Vigotsky afirma que (2010, p. 260):

[...] os conceitos científicos não são assimilados nem decorados pela criança, não são memorizados, mas surgem e se constituem por meio de uma imensa tensão de toda a atividade do seu próprio pensamento. Daí a inevitabilidade implacável de que o desenvolvimento dos conceitos científicos deva revelar em toda a plenitude as peculiaridades dessa natureza ativa do pensamento infantil.

Sendo assim, podemos inferir que o conceito espontâneo e o científico estão inevitavelmente interligados, dialogam constantemente de tal modo que o próprio desenvolvimento do conceito científico apoia-se no conceito espontâneo. Como explica Vigotsky (2010, p.261), “a experiência imediata nos ensina que o desenvolvimento dos conceitos científicos só se torna possível depois que os conceitos espontâneos da criança atingiram um nível próprio do início da idade escolar". Não podemos, simplesmente, descartar o conceito espontâneo do aluno, contrariamente, é preciso fortalecê-lo para que em suas bases se sustente o desenvolvimento dos conceitos científicos.

As generalizações que se materializam em conceitos espontâneos sobre os fenômenos do mundo das ciências devem ser de conhecimento do professor para que possa, no trabalho educativo, impulsioná-las na formação dos conceitos científicos. Entendemos que esse processo de desenvolvimento do conceito do aluno se dá pela hibridização do conceito científico com o 
conceito espontâneo. O fato a ser observado é que, independentemente de se tratar do desenvolvimento dos conceitos espontâneos ou científicos, é um processo único de formação de conceitos que se realiza sob diferentes condições internas e externas, mas continua indivisível por sua natureza.

Isso posto, para compreender a formação dos conceitos científicos primeiramente devese conhecer o processo de formação dos conceitos espontâneos.

$\mathrm{Na}$ idade escolar, o aluno traz do seu mundo - casa, igreja, bairro, relações extraescolares - um grande número de conceitos espontâneos formados no cotidiano, de forma empírica, que devem ser levados em consideração pelo professor. Cabe a ele discernir esses conceitos e perceber que nesse intrincado processo do desenvolvimento dos conceitos espontâneos há potencialmente elementos que remetem aos conceitos científicos.

[...] os conceitos científicos, que se formam no processo de aprendizagem, distinguem-se dos espontâneos por outro tipo de relação com a experiência da criança, outra relação sua com o objeto desses ou daqueles conceitos, e por outras vias que eles percorrem do momento da sua germinação ao momento da informação definitiva (VIGOTSKY, 2010, p.263).

“A força e a fraqueza dos conceitos espontâneos e científicos no aluno são inteiramente diversas: naquilo em que os conceitos científicos são fortes os espontâneos são fracos, e viceversa" (VIGOTSKI, 2010, p. 263). Por isso, o ensino dos conceitos científicos precisa acolher os diferentes conceitos espontâneos do aluno, suas generalizações no mundo das ciências, a fim de organizar atividades de estudo que possibilitem os passos necessários para alcançar os conceitos científicos, de forma a contrabalançar a força e a fraqueza de ambos.

Ao planejar o ensino, as atividades em sala de aula devem se apoiar na transição dos conceitos espontâneos oportunizando que novas generalizações caminhem em direção à apropriação do conceito cientifico. É esse tipo de ensino que promove a aprendizagem significativa que por sua vez impulsiona o desenvolvimento da personalidade do aluno.

[...] a formação dos conceitos científicos, na mesma medida que os espontâneos, não termina, mas apenas começa no momento em que a criança assimila pela primeira vez um significado ou termo novo para ela, que é veículo de conceito científico. Essa é a lei geral do desenvolvimento do significado das palavras, à qual estão igualmente subordinados em seu desenvolvimento tanto os conceitos científicos quanto os espontâneos (VIGOTSKY, 2010, p.265).

A assimilação do significado ou termo novo e o seu posterior desenvolvimento é apresentada em fases com propriedades bem características, levando em consideração as relações interpsíquicas do aluno e as ações mentais que desenvolve nesse processo, denominadas intrapsíquicas. As bases da formação dos conceitos espontâneos, de acordo com 
Vigotsky (2010), são o pensamento sincrético, o pensamento por complexo e o pré-conceito para chegar ao conceito científico.

Pode-se inferir que não há uma única via para a formação dos conceitos científicos, assim não basta apenas compreender as relações do significado difuso da palavra, a forma de pensamento por complexo e a formação dos pré-conceitos. É necessário que o professor compreenda os vínculos entre essas estruturas nas relações que estabelecem entre si, e também compreender que o desenvolvimento das funções psicológicas superiores se dá sempre em suas relações interfuncionais.

Por conseguinte, há necessidade de o professor observar a relação de generalidade de qualquer conceito que aponta a estrutura das relações que se estabelecem entre si. Nesse sentido,

Ser significado é o mesmo que estar em determinadas relações de generalidade com outros significados, isto é, significa uma medida específica de generalidade. Deste modo, a natureza do conceito - sincrética, complexa, pré-conceitual - se revela de forma mais completa nas relações específicas de dado conceito com outros conceitos (VIGOTSKY, 2010, p.368).

É por isso que a natureza dos conceitos espontâneos e científicos e todas as suas propriedades são diferentes. Vigotsky (2010, p.369) acrescenta que no interior de cada uma dessas esferas "revelam-se outras propriedades determinadas pela natureza do conceito: a) outra relação com o objeto e com o significado da palavra; b) outras relações de generalidade; c) outro círculo de operações".

Diante do exposto, entendemos que as generalizações do aluno se formam com base nas generalizações anteriores, e nasce da generalização de objetos que o pensamento já estruturou anteriormente, não como se fosse uma nova maneira de generalizar objetos singulares. Tratase, pois, de um sistema de formação dos conceitos. (VIGOTSKI, 2010).

É a descoberta do auto-movimento que faz o aluno no processo de formação de novos conceitos científicos e os seus vínculos interiores que explica como os conceitos espontâneos são incorporados pelos conceitos científicos. Compreendendo a natureza e a estrutura de ambos o professor pode planejar o ensino para desenvolver o pensamento teórico do aluno. Nessa transição é possível observar que nos estágios de desenvolvimento do conceito até sua abstração há sempre uma relação de dependência, não só o movimento entre os estágios no desenvolvimento dos conceitos é necessário, mas também o movimento dentro do próprio estágio de desenvolvimento do conceito por meio de generalizações. 


\section{CONSIDERAÇÕES FINAIS}

A concepção de aluno neste estudo é de um ser historicamente situado, capaz de intervir e participar da realidade. Nessa perspectiva, o aluno desde a educação infantil é capaz de intervindo na realidade constituindo-se na relação com o outro. Isso supõe que o aluno seja sujeito de sua atividade na escola.

O desenvolvimento do pensamento generalizante torna-se instrumento necessário de modo a possibilitar a elaboração de conceitos que levam à compreensão dos objetos materiais e imateriais. Para isso é fundamental entender as relações entre o pensamento e a linguagem no processo de formação dos conceitos científicos pelo aluno. Em relação ao papel da linguagem e do pensamento em suas relações para o ensino, o pensamento generalizante e a linguagem organizam o real, desenvolvendo todas as manifestações do pensamento em categoria conceitual.

O pensamento verbal como uma unidade de análise do pensamento e da linguagem contém as propriedades inerentes de ambas as funções psicológicas. Tendo como unidade o significado, este muda no processo de generalizações que os alunos fazem até chegarem aos conceitos científicos. Portanto, o papel da linguagem e do pensamento é promover as generalizações no processo de formação dos conceitos científicos.

O conceito como ato de generalização que se transforma e muda seus significados, constantemente, difere da simples memorização, no ensino tradicional em que mecanicamente os alunos decoram definições esvaziadas de significados. O ensino que impulsiona o desenvolvimento do aluno, no processo de formação de conceitos científicos, é aquele que incide em sua zona de desenvolvimento iminente, criando condições para que realize, com a ajuda de alguém mais experiente, aquilo que ainda não pode fazer sozinho.

No processo de formação dos conceitos científicos, o aluno realiza atividades atividade externa e interna, o que possibilita a formação dos conceitos científicos, de maneira a superar o espontaneísmo, o senso comum, o pensamento ingênuo. Para isso, a escola precisa se situar na esfera complexa de atividades, caminho para os alunos alcançam os conceitos científicos.

O ensino dos conceitos científicos a partir da incorporação dos conceitos espontâneos se dá por meio de generalizações que permitem ao aluno começar a pensar conceitualmente, sendo que ao dominar uma determinada estrutura conceitual não abandona a estrutura conceitual anterior, até a formação dos conceitos científicos. Nesse processo, os alunos desenvolvem o pensamento teórico. 
Cabe ao professor, em seu papel de pesquisador, mediar os conhecimentos científicos necessários à formação dos conceitos científicos que se deseja alcançar. A escola deve se situar na esfera complexa da atividade humana fazendo a ponte com os conhecimentos da atividade empírica na vida. Nesse contexto, o papel do professor como organizador do trabalho educativo é essencial para o desenvolvimento integral de seus alunos.

\section{REFERÊNCIAS}

DAVIDOV, Vasili V. La enseñanza escolar y el desarrollo psíquico: investigación psicológica teórica y experimental. Tradução de Marta Suare. Moscú: Editorial Progreso, 1988.

DUARTE, Newton. Educação escolar, teoria do cotidiano e a escola de Vigotski. 3. ed. Campinas: Autores Associados, 2001.

LEONTIEV, Anton N. Actividad, Consciencia y Personalidad. Havana: Pueblo y Educación, 1983.

. O desenvolvimento do psiquismo. $2^{\mathrm{a}}$ ed. São Paulo: Centauro, 2004.

MARINO FILHO, Armando. A atividade de estudo no ensino fundamental: necessidade e motivação. 2011. 237 f. Tese (Doutorado em Educação) - Faculdade de Filosofia e Ciências, UNESP, Marília, 2011.

VIGOTSKI, Lev. S. Obras Escogidas. Madri: Visor, 2000. Volume III.

. Obras Escogidas. Madri: Visor, 2001. Volume II.

Obras Escogidas. Madri: Visor, 2006. Volume IV.

. A construção do pensamento e da linguagem. 2 ed. São Paulo: Martins Fontes, 2010.

\section{SOBRE OS AUTORES}

Thiago Guimarães da Silva é docente na Universidade de Uberaba e Mestre em Educação pela mesma instituição.

E-mail: thiago.silva@uniube.br

Ana Maria Esteves Bortolanza tem Pós-doutorado pela Universidade de Évora (Portugal) e Doutorado pela Universidade Estadual Paulista Júlio de Mesquita Filho (UNESP). É docente do Mestrado Profissional em Educação da Universidade de Uberaba e líder do Grupo de Estudos e Pesquisas Infância e Contextos Educativos (GEPICE).

E-mail: anamariaestevesbortolanza@gmail.com 